\title{
AMBIGÜIDADE E REPETIÇÃO EM NON OU A VÃ GLÓRIA DE MANDAR
}

\author{
Emílio C. R. Maciel \\ Universidade Federal de Minas Gerais
}

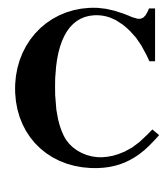

ompreendendo quase vinte ítens, a filmografia de Manoel de Oliveira constrói-se, com freqüência, como um aberto diálogo com a tradição literária do Ocidente, e adquire, em obras como "O convento" e "Francisca", a forma de um requintado jogo intertextual. Contudo, dentre os filmes que nos chegaram, em nenhum deles o referido jogo parece ser tão explícito quanto em Non ou a vã glória de mandar, cujo próprio título, aliás, é elaborado sintomaticamente a partir de uma junção de trechos de Camões e Vieira.

Filmado em 1990, trata-se, com efeito, de um dos mais ambiciosos filmes do veterano diretor. Construído por encadeamento de "flash backs", o seu presente diegético situa-se nos estertores do salazarismo, durante uma das guerras coloniais, e encontra como foco um pequeno grupo de soldados portugueses. Esses soldados, enquanto esperam a próxima batalha, acomodam-se então para ouvir os episódios narrados por um deles, versando sobre momentos vários da história lusa.

Assim, tendo como suporte narrações orais, o filme se desenrola de maneira rapsódica, através de um desenho que, pelas remissões frequentes ao passado, poderia nos lembrar a velha epopéia, tanto temática quanto formalmente. Nesse aspecto, em contraste, por exemplo, com o que ocorre no romance, que na maioria das vezes pressupõe um mundo marcado pela fragmentação ideológica, o emprego do registro oral parece solicitar, como uma espécie de fundo sobre o qual se ergue, uma certa comunidade de valores, que caberia às histórias contadas dar endosso. E, não por acaso, se 
considerarmos o conjunto das narrativas do filme, veremos que estas costumam centrar-se basicamente sobre um problema, que consiste na tentativa de consolidar a chamada "nação portuguesa". No entanto, a diverso do que é praxe nas histórias fundadoras, o desfecho desses episódios encerra uma conotação fortemente pessimista, contrariando, portanto, a função precípua da épica ortodoxa, que visa sempre o reforço de um dado arcabouço de crenças. Ao mesmo tempo, por sua desvinculação de qualquer utilidade prática imediata, o tratamento do registro oral tende a distanciar-se das teorizações do Walter Benjamin de "O narrador", apontando menos para a nostalgia de uma verdade comunitária do que para um esforço bastante claro de estilização, que dá às narrações um certo ar de conto da carochinha. Cabe frisar, todavia, que antes que servir como um apaziguador, essa estilização maciça filtra-se em "Non..." como um discurso de talhe anti-apologético, no qual a história emerge como um desfile de derrotas, em permanente marcha para o entrópico. Um pesadelo, enfim, de que Oliveira tentaria sem sucesso nos despertar.

Mas essa reiteração de desastres não se resume no filme à mera corroboração de uma neurose coletiva. Na verdade, tendo em vista o contexto em que as narrações ocorrem, não seria despropositado atribuir a elas uma função de solapar eventuais entusiasmos ufanistas; cumprindo um papel que poderia dizer-se análogo ao do velho do Restelo em "Os lusíadas". Por este ponto de vista, mais do que restringir-se à chorumela, a insistente rememoração das derrotas pregressas procuraria antes agir criticamente sobre o presente, reduzindo pretensões colonialistas à sua devida dimensão de falácia. De modo que, se considerados seus possíveis efeitos, a atualização do pretérito ganharia aí o peso de um trabalho retórico, e compreenderia pois uma tática para afirmar uma dada mensagem moral, cujo foco se centra sobre a "Vã glória de mandar" citada no título.

O mais interessante, entretanto, é que na medida em que se reiteram, estas supostas lições acabam por se voltar contra si próprias, ao delatarem, na sua exasperante tautologia, um trabalho que poderíamos chamar de mítico. Tal trabalho, negando a especifici- 
dade dos momentos históricos, concorre então para fazer com que os fatos sejam enquadrados numa lei mecânica, na qual se corrobora uma idéia de essência, uma certa vocação para o fracasso, que é apanágio de cada narrativa desvelar. Algo que se torna bem claro, por exemplo, na seqüência referente à batalha de Alcácer-Quibir, quando, num clamoroso mas elucidativo anacronismo, um soldado agonizante aparece esbravejando um trecho de sermão do padre Vieira, o grande mestre dos "sentidos predicáveis". No trecho citado, tomando por base a palavra "non", Vieira opera mais uma de suas analogias vertiginosas, ao fazer da reversibilidade da dita palavra o emblema de uma ciclicidade diabólica. Com isso, quando é inserido esse fragmento, o discurso do filme parece também morder sua própria cauda, reforçando ainda mais o talhe mítico do todo. E isso justo naquele que parece ser o momento mais escabroso da história portuguesa: o do desaparecimento do para sempre esperado don Sebastião.

Acresce que, de vez que essa nota vai se repetindo, o seu fatalismo exacerbado acaba por trair a seletividade do narrador, que, no fluxo conturbado da história, pinça apenas os eventos que corroboram suas idéias. Em simultâneo, ao evidenciar essa manipulação, tal montagem tinge de ironia a suposta seriedade das mensagens éticas, ao mostrar como toda tentativa de construir o passado é indissociável de uma dada margem de injustiça, resultante da valorização de alguns acontecimentos em detrimento de outros. Sendo assim, mais do que apenas engajar-se contra a ideologia salazarista, as escolhas feitas pelo narrador oral implicam ainda, no limite, o próprio esvaziamento de seu poder persuasivo, à proporção que, depois de tantos episódios calamitosos, o propósito gnômico do discurso deixa-se relativizar por aquilo que tem de calculado.

Neste instante, contudo, alguém que houvesse assistido ao resto do filme poderia assinalar, como exceção a essa regra, o fragmento da Ilha dos Amores (referente aos últimos dois cantos de "Os Lusíadas"), enxergando aí um tipo de presentificação utópica, que em muito destoa da coda derrotista do que o precede. 
Entretanto, o próprio estilo com que este episódio é encenado - num registro "kitsch" provocativamente iconoclasta - acaba por desautorizar essa suspeita de incoerência, graças ao lastro de uma negatividade menos ostensiva, mas não menos mortal que as anteriores. Nesse desenho, a realização da plenitude só poderia ocorrer sob uma forma degradada, na figuração de uma beleza formalmente prostituída, e que para os olhos mais treinados dos espectadores, nada mais é que uma outra variante do pesadelo.

Note-se também que, mesmo parecendo um desvirtuamento mal intencionado, esse mergulho no kitsch pode ser entendido, em clave oblíqua, como um modo de tornar evidente a artificiosidade da cena toda, atuando então como um componente anti-ilusionista. E não estando muito longe assim da maneira como, no poema camoniano, as deidades clássicas se auto-proclamam como convencionais, reduzidas que se acham a meros pretextos para o engenho do poeta. Condição essa que poderia ser confirmada pela fala inicial da ninfa Thetis, na qual a existência da "Ilha afortunada" decodificase em um plano puramente alegórico.

Num sentido mais amplo, portanto, as aparentes arestas do filme tendem a se conciliar em um discurso inteiriço, onde todo o esboço de glória passada é submetido a um aniquilamento impiedoso, seja pelo desfecho dos episódios, seja pelo tipo de tratamento que lhes é dado. Porém, malgrado o que tenha de implacável, um aniquilamento desse naipe acaba por também produzir novas arestas, uma vez que, por mais monolítico que seja o passado, o simples fato de que este se preste a interpretações já acarreta de, per si, a admissão de um limiar de polissemia. E se levarmos esse raciocínio até o fim, a referida polissemia poderia aludir à presença de um mistério insondável, cuja recorrência no tempo é a condição sem a qual nenhuma narrativa se erige.

Por outro lado, levando-se em conta a maneira como um sentido é por elas estabilizado, as narrativas em questão poderiam quem sabe apontar, como seu plausível "motor primeiro", para o atordoante plano-seqüência inicial, talvez o mais belo de todo o 
filme. Neste plano, tendo por fundo uma inquietadora trilha minimalista, a câmera do diretor vai aproximando-se de uma grande árvore e depois dela se afasta paulatinamente, enquanto a tensão criada entre som e imagem produz aí a sensação de um mistério a ser decifrado: um mistério, no entanto, que a exemplo do que ocorre em outros filmes de Oliveira, haverá de restar indecifrável. Como se, à vista dos desdobramentos posteriores, à impassibilidade daquela árvore coubesse fornecer um determinado montante de angústia, que se tentaria ver sublimado pelo fabular. Ou como se, diante do alheamento da natureza, nada mais restasse além da busca ansiosa de uma significação cultural, que pudesse proporcionar-nos a miragem de um sentido.

Importa frisar, entretanto, que tal como configurada no filme, essa almejada significação deverá sempre lastrear-se de grande ambigüidade, podendo remeter-nos ora à derrota vista como destino, ora à ironização hiperbólica da mesma. Nesse aspecto, aliás, não deixa de ser intrigante que, no plano que fecha todo o filme, haja uma referência cruzada à Revolução dos Cravos, que coincide com o dia da morte do soldado-narrador. Uma lembrança, em suma, que depois de tantas derrotas acumuladas, talvez possa mesmo ser lida como um aceno à esperança. Ou talvez não. 


\section{Resumo}

No presente ensaio, nossa proposta é analisar o filme Non ou a vã glória de mandar, de Manoel de Oliveira, com ênfase em suas relações com a literatura e a história portuguesas. Para tanto, em um primeiro momento, centraremos nosso foco sobre o modo como a recuperação do passado, através de um amálgama de fatos e citações, concorre aí para a transformação da suposta realidade em um discurso, que se serve do potencial manipulador da montagem e, ao mesmo tempo, leva esse potencial à exaustão. Assim, considerando as aporias que o filme gera, procuraremos demonstrar como a repetição obsessiva de um "tropo" - o tema da vontade-de-poder fracassada - ao invés de contribuir para o reforço de uma idéia, acaba antes por ocasionar sua subversão gradativa. Em conseqüência, a possibilidade de um sentido uno, ao ser permeada por uma dúvida crescente, tenderá a transformar toda busca de fechamento em um esforço fadado ao fracasso, realçando, com isso, a inesgotabilidade última do texto fílmico em questão. Texto, esse, que será aqui lido como uma espécie de máquina perversa, voltada integralmente para a produção e reprodução da ambigüidade.

\section{Abstract}

In this essay, our purpose is to analyse the film Non ou a vã glória de mandar, emphasizing its relationships with the portugese literature and history. For this matter, at first, we will focus on how the rescue of the past, trough an amalgam of facts and quotations, contributes to transform the assumed reality in a discourse, which takes advantage of the manipulative power of the editing and, at the same time, brings this power to a exaustion. Hence, considering the apories that the filme creates, we will try to show how the obsessive repetition of a topic - the theme of the deluded will to power instead of endorsing the idea, causes its gradual subversion. Consequently, the possibility of a single sense, perpassed by a crescent doubt, will tend to convert every search for a closure in a effort destinated to failure, highlightining therefore the restlesness of the filmic text: a text that will be read now as a kind of perverse machine, integrally turned to the production and reproduction of ambiguity. 